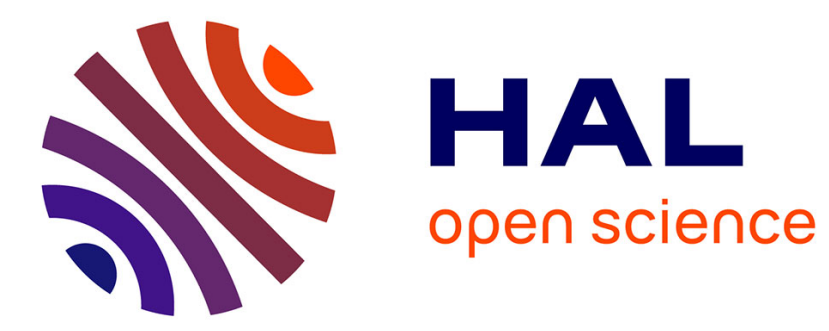

\title{
Acute, major muscular hematoma associated with antithrombotic agents: A multicenter real-world cohort
}

Jacques Bouget, Marie-Clémence Huet, Pierre-Marie Roy, Damien Viglino, Karine Lacut, Laure Pavageau, Emmanuel Oger

\section{- To cite this version:}

Jacques Bouget, Marie-Clémence Huet, Pierre-Marie Roy, Damien Viglino, Karine Lacut, et al.. Acute, major muscular hematoma associated with antithrombotic agents: A multicenter real-world cohort. Thrombosis Research, 2021, 199, pp.54-58. 10.1016/j.thromres.2020.12.022 . hal-03129761

\section{HAL Id: hal-03129761 \\ https://hal.science/hal-03129761}

Submitted on 5 Feb 2021

HAL is a multi-disciplinary open access archive for the deposit and dissemination of scientific research documents, whether they are published or not. The documents may come from teaching and research institutions in France or abroad, or from public or private research centers.
L'archive ouverte pluridisciplinaire HAL, est destinée au dépôt et à la diffusion de documents scientifiques de niveau recherche, publiés ou non, émanant des établissements d'enseignement et de recherche français ou étrangers, des laboratoires publics ou privés. 


\section{Acute, major muscular hematoma associated with antithrombotic agents: a multicenter real-world cohort}

Jacques Bouget ${ }^{\mathrm{a}}$, Marie-Clémence Huet ${ }^{\mathrm{b}}$, Pierre-Marie Roy ${ }^{\mathrm{c}}$, Damien Viglino ${ }^{\mathrm{d}}$, Karine Lacut ${ }^{\mathrm{e}}$, Laure Pavageau ${ }^{\mathrm{f}}$, Emmanuel Oger $^{\mathrm{a}}$

${ }^{a}$ Univ Rennes, CHU Rennes, EA 7449 [Pharmacoepidemiology and Health Services Research] REPERES, F 35043 Rennes

${ }^{\mathrm{b}}$ Emergency Department, Rennes University Hospital, F 35033 Rennes, France

${ }^{c}$ Emergency Department, Centre Hospitalier Universitaire, Institut MITOVASC, Université d'Angers, Angers, France; F-CRIN INNOVTE, France

${ }^{\mathrm{d}}$ Emergency Department, Grenoble-Alpes University Hospital, F 38043 Grenoble, France ${ }^{\text {e }}$ CIC 1412, Université de Bretagne Loire, Université de Brest, INSERM CIC 1412, CHRU de Brest, F 29200 Brest

${ }^{\mathrm{f}}$ Emergency Department, University hospital, F 44093 Nantes, France

Correspondence to: Emmanuel OGER emmanuel.oger@univ-rennes1.fr, phone +33223234713, University of Rennes 1, EA 7449 [Pharmacoepidemiology and Health Services Research] REPERES, F 35043 Rennes

Word count of the main text: 2757 


\section{ABSTRACT}

Background: There is little data on major muscular hematomas and the little there is has mainly focused on patients exposed to oral anticoagulants.

Objective: To describe the clinical characteristics, management and outcomes of patients admitted to emergency department (ED) for major muscular hematoma associated with an antithrombotic agent, and to identify predictors of in-hospital mortality.

Patients and Methods: Over a three-year period, all consecutive cases of adult patients admitted to the ED of 5 tertiary care hospitals for major muscular hematoma while exposed to an antithrombotic agent were prospectively collected and medically validated. Clinical and biological data, therapeutic management of the bleeding event, and in-hospital mortality were collected from the medical records and compared across five groups of hematoma locations. Potential confounders were taken in account using a multivariate binomial regression model. Results: Three hundred and seventy-five patients were included (mean age $=81.4$ years): 271 were exposed to vitamin K antagonists, 58 to parenteral anticoagulants (heparin, LMWH, fondaparinux), 33 to antiplatelets, and 13 to direct oral anticoagulants. The muscular hematomas were located in the lower limbs $(n=198)$, the rectus sheath $(n=71)$, the iliopsoas $(\mathrm{n}=45)$, the upper limbs $(\mathrm{n}=33)$, or elsewhere $(\mathrm{n}=28)$. Reversal therapy was prescribed for $48.5 \%$ of patients, red cell transfusions for $63.6 \%$, surgery for $12.3 \%$ and embolization for $3.5 \%$. For $84 \%$ of patients, hospitalization was required, with a median length of stay of 10 days. Overall, in-hospital mortality was $8.5 \%$. Reversal therapy, the need for intensive care and mortality were significantly more frequent among patients with iliopsoas hematomas. The independent predictors of in-hospital mortality were: decrease in mean arterial pressure $(\mathrm{RR}=$ $1.84)$, decrease in hemoglobin level $(\mathrm{RR}=1.37)$ and the iliopsoas location $(\mathrm{RR}=3.06)$.

Conclusion: Frail elderly patients with major muscular hematomas linked to antithrombotic agents risk substantial morbidity and in-hospital mortality. The iliopsoas location was the most life-threatening bleeding site. Close observation of this population is warranted to ensure better outcomes.

Word count of the abstract: 328

Keywords: Hematoma, antithrombotic agents, vitamin K, prothrombin complex concentrates, case management, mortality 


\section{Introduction}

Major bleeding is the most feared complication among patients exposed to antithrombotic agents. Most studies have focused on the two main bleeding complications, gastrointestinal bleeding and intracranial hemorrhage [1-4]. Few studies have reported on major muscular hematomas [5]. There is sparse, imprecise data on the incidence, morbidity and mortality of muscular hematomas associated with antithrombotic agents. In a 2-year study including 913 patients consecutively admitted to our emergency department with major bleeding associated with antithrombotic agents, muscular hematomas were observed for 86 patients $(9.4 \%)$, of whom $66.3 \%$ were exposed to oral anticoagulants, $19.8 \%$ to antiplatelet agents and $13.9 \%$ to parenteral anticoagulants; a one-month mortality of $4.5 \%$ was observed [6]. Most studies have reported on muscular hematomas irrespective of severity and have mainly focused on patients exposed to oral anticoagulants. In a study by $\mathrm{Xu}$ et al. [7] including 1542 patients with bleeding linked to oral anticoagulants, muscular hematomas without compartment syndrome were reported for 82 patients (5.3\%) exposed to warfarin, and for 8 patients (1.7\%) exposed to direct oral anticoagulants (DOAC). Green et al. [8] reported musculoskeletal bleeding for $10 \%$ of patients exposed to oral anticoagulants. In an Italian cohort of 806 patients with major bleeding while exposed to vitamin $\mathrm{K}$ antagonist (VKA) or DOAC, soft-tissue bleeding accounted for $11 \%$ of VKA-exposed patients and $6 \%$ of DOAC-exposed patients [9]. In a prospective multicenter study on major bleeding related to VKAs, deep-muscle hematomas accounted for $13 \%$ of bleeding events with a 7-day mortality of $4 \%$ [10]. Finally, in another study, among 80 patients on anticoagulants with spontaneous soft-tissue hemorrhage including muscular hematomas, most required transfusion, aggressive resuscitation, reversal therapy, or embolization and one-month mortality reached $11 \%$ [11].

Over a three-year period, we conducted a prospective population-based cohort study named SACHA collecting all major bleeding events occurring among patients exposed to antithrombotic agents (nearly 98,000 person-years of exposure) whatever the indication, and referred to emergency department [12,13]. The SACHA study included 6484 patients with major bleeding events, among whom 2090 (32.2\%) presented major bleeding other than gastrointestinal or intracranial hemorrhages. Of these, 375 had major muscular hematomas, amounting to $5.8 \%$ of the overall population included.

Our primary objective was to describe the clinical characteristics and the management of these 375 patients referred to emergency departments for major muscular hematomas associated with antithrombotic agents. Our secondary objective was to identify risk factors for in-hospital mortality. 


\section{Materials and Methods}

\subsection{Study design and participants}

The SACHA study is a French prospective population-based multicenter cohort study on the incidence and outcome of major bleeding among patients exposed to antithrombotic agents whatever the type (parenteral or oral anticoagulant, or antiplatelet agent) or the indication $[12,13]$.

For the current analysis, all consecutive adult patients admitted between January 1, 2013 and December 31, 2015 to the emergency departments of five tertiary care hospitals for major, acute muscular hematoma while exposed to an antithrombotic agent were included in the analysis. The severity of the bleeding was defined from at least one of the following criteria [14]: unstable hemodynamics (systolic arterial pressure $<90 \mathrm{mmHg}$ or mean arterial pressure $<65 \mathrm{~mm} \mathrm{Hg}$ ) or hemorrhagic shock, uncontrollable bleeding, need for transfusion or hemostatic procedure (embolization, surgery) and compartment syndrome. In each emergency department, the local referent medical doctor validated the final inclusion of all records screened for acute, severe bleeding. The following patients were excluded from the analysis: patients with muscular hematomas occurring during hospitalization after admission for reasons other than bleeding, and patients hospitalised for an intentional overdose of antithrombotic drugs.

No informed signed consent was required. The study was reviewed and approved by the Rennes University Hospital Review Board and received regulatory approval (CNIL, DR2013-488, with subsequent substantial changes DR-2016-489); ClinicalTrials.gov identifier: NCT02886533.

\subsection{Data source and variables}

From the emergency department clinical records, clinical and biological data were collected: demographics (age, gender), medical history, history of trauma, comorbid conditions, antithrombotic agent class (oral anticoagulants (VKA or DOAC), parenteral anticoagulants (heparin, low-molecular-weight heparin, fondaparinux), antiplatelet agents (mono or dual therapy) and any combinations), the indications for the antithrombotic agents, the type of bleeding/outcome, vital signs at admission (mean blood pressure), biological data at admission (hemoglobin and creatinine levels), management of the bleeding in the emergency department: specific emergency therapies such as red blood cell transfusion, platelet transfusion, plasma transfusion, vitamin $\mathrm{K}$, protamin sulfate, prothrombin complex concentrates (PCC) and FEIBA, and vascular or surgical procedures. From hospital medical 
records, the length of stay in hospital and in ICU, and fatalities defined as in-hospital mortality were extracted.

\subsection{Statistical analysis}

Firstly, the clinical characteristics were described according to hematoma locations divided into 5 groups: upper limb hematoma, lower limb hematoma, rectus sheath hematoma, iliopsoas hematoma, and others. The distribution of antithrombotic agent classes - oral anticoagulants (vitamin $\mathrm{K}$ antagonist, direct oral anticoagulant), antiplatelet agents (monotherapy or dual therapy), and parenteral anticoagulants (heparin, low molecular weight heparin (LMWH), fondaparinux) - was studied across hematoma locations.

Secondly, management and in-hospital mortality were compared across hematoma locations.

For the stratified statistical analysis, general association statistics were used, testing the alternative hypothesis that, for at least one stratum, there is some kind of association. Potential confounders were then taken in account in a multivariate binomial regression model. All statistical tests were two-tailed and P-values $<0.05$ were considered significant. Statistical analyses were performed using SAS software 9.4 (SAS Institute, Cary, N.C., USA). 


\section{Results}

\subsection{Clinical characteristics}

Over a 3-year period, 375 patients (mean age 81.4 years) with major muscular hematomas were included; 56.3\% were female; 293 patients (78.1\%) met the ISTH criteria [15]. Among the remaining 82 patients, 41 had either unstable hemodynamics, hemorrhagic shock, or uncontrollable bleeding. Patient enrolment was based on medical validation.

Table 1 shows the clinical characteristics, comorbidities, and biological data recorded at admission according to hematoma location. The distribution of muscular locations was as follows: lower limb hematoma $(n=198)$, rectus sheath hematoma $(n=71)$, iliopsoas hematoma $(n=45)$, upper limb hematoma $(n=33)$, other locations $(n=28$, including gluteal $n=6$, latissimus dorsi $n=5$, pectoralis $n=5$, miscellaneous $n=3$, and non-determined $n=9$ ). A history of trauma was reported for about half of the population, especially among patients with limb hematomas. Ground-level falls were the predominant cause of injury.

The distribution of antithrombotic agents according to hematoma location is shown in Appendix A Table A.1. For three quarters of the patients (284/375, 75.7\%), muscular hematomas were associated with oral anticoagulants, mostly VKAs $(n=271,95.4 \%)$ rather than DOACs $(\mathrm{n}=13,4.6 \%)$.

The indications for antithrombotic agents are reported in Appendix A Table A.2. The main indication for oral anticoagulants was atrial fibrillation (AF) $(60.5 \%$ for VKA and 69.2\% for DOAC) followed by venous thromboembolism (VTE). Antiplatelet agents were prescribed to patients with stroke and coronary disease.

\subsection{Management of the bleeding event}

For the entire population, reversal therapy (vitamin K and/or PCC) was prescribed to 182 (48.5\%) patients (Appendix A Table A.3). Red blood cell transfusions were required for 235 $(63.6 \%)$ patients. For 46 (12.3\%) patients, surgery was required for compartment syndrome. Thirteen (3.5\%) required embolization. Hospitalization was required for $84 \%$ of the overall population with a median length of stay of 10 days.

Appendix A Table A.4 shows the management of the bleeding event among patients receiving VKAs according to hematoma location. Reversal therapy using vitamin K or PCC was prescribed more often to patients with iliopsoas hematomas than to patients with other hematoma locations $(\mathrm{p}=0.005)$. Red blood cell transfusions were needed for $60 \%$ of the overall population. For 14 patients with lower limb hematoma and 9 patients with upper limb hematoma, surgery was required for compartment syndrome. 
Table 1

Baseline characteristics according to hematoma location. Values are Frequency (Percent), or mean \pm SD, MAP stands for Mean arterial pressure, GI for gastrointestinal, and IC for intracranial. P-value based either on chi-square test, Fisher's exact test or Kruskall-Wallis' test.

\begin{tabular}{|c|c|c|c|c|c|c|c|}
\hline & $\begin{array}{l}\text { Overall } \\
\mathrm{N}=375\end{array}$ & $\begin{array}{l}\text { Lower limb } \\
\mathrm{N}=198\end{array}$ & $\begin{array}{l}\text { Upper limb } \\
\mathrm{N}=33\end{array}$ & $\begin{array}{l}\text { Rectus sheath } \\
\mathrm{N}=71\end{array}$ & $\begin{array}{l}\text { Iliopsoas } \\
\mathrm{N}=45\end{array}$ & $\begin{array}{l}\text { Other } \\
\mathrm{N}=28\end{array}$ & p-value \\
\hline Gender, female & $211(56.3)$ & $121(61.1)$ & $19(57.6)$ & $41(57.7)$ & $15(33.3)$ & $15(53.6)$ & 0.020 \\
\hline Age, years & $81.4 \pm 10.8$ & $82.2 \pm 11.1$ & $81.7 \pm 12.2$ & $81.1 \pm 9.60$ & $78.3 \pm 10.8$ & $81.0 \pm 9.4$ & 0.052 \\
\hline Cancer & $38(10.1)$ & $22(11.1)$ & $4(12.1)$ & $4(5.6)$ & $6(13.3)$ & $2(7.1)$ & 0.589 \\
\hline Arterial hypertension & $227(60.5)$ & $113(57.1)$ & $22(66.7)$ & $46(64.8)$ & $29(64.4)$ & $17(60.7)$ & 0.673 \\
\hline Diabetes mellitus & $55(14.7)$ & $30(15.1)$ & $3(9.1)$ & $8(11.3)$ & $10(22.2)$ & $4(14.3)$ & 0.468 \\
\hline Coronary artery disease & $90(24.0)$ & $52(27.3)$ & $6(18.2)$ & $20(28.2)$ & $7(15.6)$ & $5(17.9)$ & 0.382 \\
\hline Cardiac insufficiency & $66(17.6)$ & $32(16.2)$ & $7(21.2)$ & $16(22.5)$ & $8(17.8)$ & $3(10.7)$ & 0.611 \\
\hline Cardiac valvulopathy & $47(12.5)$ & $19(9.6)$ & $5(15.1)$ & $13(18.3)$ & $9(20.0)$ & $1(3.6)$ & 0.082 \\
\hline Lower limb arteriopathy & $53(14.1)$ & $31(15.7)$ & $6(18.2)$ & $7(9.9)$ & $4(8.9)$ & $5(17.9)$ & 0.520 \\
\hline Ischemic stroke & $81(21.6)$ & $40(20.2)$ & $9(27.3)$ & $15(21.1)$ & $11(24.4)$ & $6(21.4)$ & 0.897 \\
\hline History of bleeding & $75(20.0)$ & $37(18.7)$ & $8(24.2)$ & $14(19.7)$ & $11(24.4)$ & $5(17.9)$ & 0.874 \\
\hline GI bleeding & 24 & 14 & 2 & 4 & 2 & 2 & \\
\hline IC bleeding & 11 & 4 & 1 & 3 & 3 & - & \\
\hline Other & 40 & 19 & 5 & 7 & 6 & 3 & \\
\hline Gastro-duodenal ulcer & $17(4.5)$ & $9(4.55)$ & - & $4(5.6)$ & $4(8.9)$ & - & 0.335 \\
\hline Liver cirrhosis & $4(1.1)$ & $2(1.01)$ & $1(3.0)$ & - & $1(2.2)$ & - & 0.404 \\
\hline Chronic renal failure & $59(15.7)$ & $21(10.6)$ & $10(30.3)$ & $14(19.7)$ & $11(24.4)$ & $3(10.7)$ & 0.010 \\
\hline Current smoking & $13(3.5)$ & $4(2.0)$ & $1(3.0)$ & $4(5.6)$ & $2(4.4)$ & $2(7.1)$ & 0.268 \\
\hline Alcoholism & $22(5.9)$ & $8(4.0)$ & $6(18.2)$ & $4(5.6)$ & $1(2.2)$ & $3(10.7)$ & 0.021 \\
\hline MAP (mm Hg) & $82.7 \pm 17.0$ & $83.3 \pm 17.3$ & $83.2 \pm 18.0$ & $84.0 \pm 13.6$ & $78.2 \pm 18.9$ & $81.8 \pm 18.0$ & 0.501 \\
\hline Creatinine $(\mu \mathrm{mol} / \mathrm{L})$ & $114 \pm 72$ & $102 \pm 52$ & $129 \pm 86$ & $118 \pm 86$ & $157 \pm 99$ & $103 \pm 56$ & $<.001$ \\
\hline Hemoglobin (g/dL) & $9.6 \pm 2.5$ & $9.2 \pm 2.3$ & $10.2 \pm 2.5$ & $10.4 \pm 2.1$ & $9.7 \pm 2.9$ & $10.1 \pm 3.0$ & $<.001$ \\
\hline Trauma & $171(45.6)$ & $102(51.5)$ & $20(60.6)$ & $22(31.0)$ & $10(22.2)$ & $17(60.7)$ & $<.001$ \\
\hline Minor & 16 & 11 & 3 & 1 & - & 1 & \\
\hline Ground-level falls & 129 & 77 & 14 & 16 & 8 & 14 & \\
\hline Major fall & 14 & 8 & 2 & 1 & 1 & 2 & \\
\hline Traffic injury & 6 & 4 & - & 2 & - & - & \\
\hline Context lacking & 6 & 2 & 1 & 2 & 1 & - & \\
\hline
\end{tabular}




\subsection{Predictors of in-hospital mortality}

Overall in-hospital mortality was $8.5 \%$, higher among patients with iliopsoas hematoma than among patients with other hematoma locations $(\mathrm{p}=0.015)$ (Appendix A Table A.5). The univariate and multivariate analyses for predictors of in-hospital mortality are reported in Table 2. Age, gender, hematoma location, reversal therapy, surgery, embolization, class of antithrombotic agents, trauma, and biological data at admission were variables used in the univariate analysis. Iliopsoas hematoma $(\mathrm{RR}=3.06,95 \% \mathrm{CL}: 1.69-6.73)$, a 20-unit decrease in mean arterial pressure $(\mathrm{RR}=1.84,95 \% \mathrm{CL}: 1.20-2.82)$ and a 2 -unit decrease in hemoglobin level $(\mathrm{RR}=1.37,95 \% \mathrm{CL}: 1.06-1.77)$ were the 3 independent predictors of in-hospital mortality.

\section{Table 2}

Predictors of in-hospital mortality (univariate analysis based on 375 observations and 32 deaths, multivariate analysis based on 361 observations). ${ }^{1}$ vitamin $\mathrm{K}$, prothrombin complex concentrate (PCC), plasma transfusion or protamin sulfate; DOAC stands for direct oral anticoagulant, $\mathrm{Hb}$ for hemoglobin, MAP for mean arterial pressure, RR for risk ratio, and CL for confidence limit.

\begin{tabular}{lcccccc}
\hline Variable & \multicolumn{3}{c}{ Univariate analysis } & \multicolumn{3}{c}{ Multivariate analysis } \\
& RR & $95 \%$ CL & RR & 95\%CL \\
\hline Hematoma location & & & & & & \\
$\quad$ Lower limb & 1.00 & & & & & \\
$\quad$ Upper limb & 2.11 & 0.72 & 6.25 & 1.73 & 0.54 & 5.61 \\
$\quad$ Rectus sheath & 1.25 & 0.45 & 3.46 & 1.62 & 0.58 & 4.49 \\
$\quad$ Iliopsoas & 3.88 & 1.76 & 8.57 & 3.06 & 1.69 & 6.73 \\
$\quad$ Other location & 0.99 & 0.23 & 4.31 & 0.99 & 0.25 & 3.99 \\
Trauma & 0.71 & 0.36 & 1.42 & & & \\
Antithrombotic agents & & & & & & \\
$\quad$ Vitamin K antagonist & & & & & & \\
$\quad$ DOAC & 0.83 & 0.12 & 5.69 & & & \\
$\quad$ Antiplatelet agent & 0.33 & 0.05 & 2.35 & & & \\
$\quad$ Heparin & 0.87 & 0.31 & 2.38 & & & \\
$\quad$ Fondaparinux & 1.35 & 0.21 & 8.80 & & & \\
Specific reversal therapy ${ }^{1}$ & 1.20 & 0.62 & 2.33 & & & \\
Surgery & 0.47 & 0.12 & 1.93 & & & \\
Embolization & 1.86 & 0.49 & 6.95 & & & \\
Age, 10-year increase & 1.23 & 0.86 & 1.77 & & & \\
Female & 1.14 & 0.58 & 2.23 & & & \\
MAP (mm Hg), 20-unit decrease & 2.22 & 1.48 & 3.34 & 1.84 & 1.20 & 2.82 \\
Hb (g/dL), 2-unit decrease & 1.43 & 1.07 & 1.89 & 1.37 & 1.06 & 1.77 \\
Creatinine $(\mu$ mol/L), 20-unit increase & 1.03 & 0.95 & 1.11 & & & \\
\hline & & & & & & \\
\hline
\end{tabular}




\section{Discussion}

Our population was a large prospective cohort of 375 patients who had been prescribed some type of antithrombotic agent and who had been referred for major muscular hematomas. To include a population that was as homogenous as possible, strict criteria were used to define major bleeding, based on the French guidelines [14]; however, we acknowledge that there was a slight alteration with respect to the International Society on Thrombosis and Hemostasis (ISTH) classification [15]. This selected cohort corresponded to nearly half of the overall population exposed to antithrombotic agents with intramuscular hematoma, in line with Moustafa et al., who reported major muscular bleeding using the ISTH criteria for about half of his recruitment [5]. A large majority of the major muscular hematomas observed in this study were associated with oral or parenteral anticoagulants (91.2\%). Major muscular hematomas have been very rarely associated with antiplatelet agents, $8.8 \%$ in the present study and $4 \%$ in our previous study [6], irrespective of location. Indeed, only case-reports of patients with major muscular hematoma associated with antiplatelet agents were found [1620].

Except for iliopsoas hematomas, major muscular hematomas have been reported to occur o particularly among older women [21]. Trauma was reported in about half of this population, especially in the limbs, with a large predominance of ground-level falls. In our study, spontaneous hematomas were observed in rectus sheath and iliopsoas locations, which is in line with other studies [22,23].

The lower limbs are the main hematoma location. Most are post-traumatic and more than four-fifths of the patients require hospitalization. In our cohort, 14 patients (11\%) required surgical decompression and fasciotomy. This well-known complication is most common in the anterior and deep compartments of the leg [24,25]. Upper arm hematomas were observed for 33 patients (9\%). For 9 patients exposed to VKAs, surgery was required for compartment syndrome, which is an uncommon bleeding complication rarely reported in the literature. Indeed, Maeckelbergh et al. found only 13 articles reporting cases of upper arm compartment syndrome in a review of the literature [26]. Early surgery for decompression (fasciotomy) is essential to prevent irreversible muscle ischemia, tissue necrosis, permanent functional impairment and in some cases renal failure due to rhabdomyolysis [27].

Almost all patients with rectus sheath hematoma (RSH) in our study were exposed to oral or parenteral anticoagulation. RSHs have been reported among patients exposed to subcutaneous heparin and LMWH injections for atrial fibrillation or venous thromboprophylaxis, with an increased risk in the elderly population [28]. Invasive hemorrhage control should be 
considered in case of unstable hemodynamics or signs of abdominal compartment syndrome: angiography, and embolization or surgical ligation of bleeding vessels, have been reported to be safe and efficacious $[29,30]$.

Although uncommon, the most serious hematoma location is iliopsoas hematoma $[22,23,31,32]$. In the present study, $84.4 \%$ of these patients were exposed to oral anticoagulants and $13.3 \%$ to parenteral anticoagulants. This location combined all severity criteria: the most severe clinical presentations, unstable hemodynamics, hemorrhagic shock, increased creatinine levels, and high in-hospital mortality (22.2\%). Among patients receiving VKAs, reversal therapy with vitamin K and PCC was required for $75.7 \%$ and $56.8 \%$ respectively; surgery and embolization were required for $10.8 \%$ and $5.4 \%$ respectively. These elements are in line with Ljitos et al., who reported on 77 patients with iliopsoas hematoma in 3 ICUs over an 8-year period [23]. Most of them were exposed to anticoagulants (72\%), some required reversal therapy (38\%), and $22 \%$ and $9 \%$ respectively required embolization or surgery, with a high mortality of $30 \%$. As reported in the present study, the majority of iliopsoas hematomas (here 35/45) are spontaneous [22,33]. Patients with a combination of antithrombotic agents, such as heparin plus vitamin $\mathrm{K}$ antagonist or vitamin $\mathrm{K}$ antagonist plus antiplatelet agent, have been reported to be more likely to require intensive care and a longer ICU stay [34]. Iliopsoas hematoma is a potentially life-threatening site of bleeding leading to a mortality rate of 20 to $30 \%[23,31]$.

No statistical comparison between oral anticoagulants was performed, because our study was not designed for this, but previous results suggest that DOACs are associated with a lower proportion of "other" major bleeding (including muscular hematomas which account for $1 / 3$ of these events) [13].

In our cohort of cases of major intramuscular bleeding, in-hospital mortality was significant $(8.5 \%)$. Neither age, the type of antithrombotic agent nor specific reversal therapy were predictors of mortality. Compared to other locations, the iliopsoas location was a strong predictor of mortality, which is in line with other authors' findings [31,34].

In conclusion, in our study lower limb hematomas were the most frequent location, but the iliopsoas location was the most life-threatening bleeding site. Decreases in mean arterial pressure and in hemoglobin levels and the iliopsoas location were independent predictors of mortality. Physicians should be aware that intramuscular hematomas associated with antithrombotic agents can lead to significant morbidity and mortality. Close observation is warranted for these patients to ensure better outcomes. 


\section{Disclosure}

None.

\section{Funding}

Supported by National Clinical Research Hospital Program of the French Ministry of Health, No. PHRC-12-009-0243.

\section{CRediT authorship contribution statement}

Jacques Bouget: Methodology, Writing - original draft, Writing - review \& editing,

Validation, Marie-Clémence Huet: Investigation, Writing - review \& editing, Pierre-Marie Roy: Investigation, Writing - review \& editing, Damien Viglino: Investigation, Writing review \& editing, Karine Lacut: Investigation, Writing - review \& editing, Laure Pavageau: Investigation, Writing - review \& editing, Emmanuel Oger: Methodology, Formal analysis, Writing - original draft, Writing - review \& editing, Validation.

\section{Declaration of competing interest}

All authors declare no competing interests. 


\section{References}

[1] C.T. Ruff, R.P. Giugliano, E. Braunwald, E.B. Hoffman, N. Deenadayalu, M. Ezekowitz, et al., Comparison of the efficacy and safety of new oral anticoagulants with warfarin in patients with atrial fibrillation: a meta-analysis of randomised trials, Lancet. (2014), https://doi.org/10.1016/S0140-6736(13)62343-0.

[2] S. Halvorsen, W. Ghanima, I.F. Tvete, C. Hoxmark, P. Falck, O. Solli, C. Jonasson, A nationwide registry study to compare bleeding rates in patients with atrial fibrillation being precribed oral anticoagulants, Eur. Heart. J. Cardiovasc. Pharmacother. (2017), https://doi.org/10.1093/ehjcvp/pvw031.

[3] M. Melkonian, W. Jarzebowski, E. Pautas, V. Siguret, J. Belmin, C. Lafuente-lafuente, Bleeding risk of antiplatelet drugs compared with oral anticoagulants in older patients with atrial fibrillation: a systematic review and meta-analysis, J. Thromb. Haemost. (2017), https://doi.org/10.1111/jth.13697.

[4] Y. Vinogradova, C. Coupland, T. Hill, J. Hippisley-Cox, Risks and benefits of direct oral anticoagulants versus warfarin in a real world setting: cohort study in primary care, BMJ. (2018), https://doi.org/10.1136/bmj.k2505.

[5] F. Moustafa, L. Poujol, N. Vincent, J. Saint-Denis, N. Dublanchet, N. Breuil, et al, Characteristics and outcomes of reversed patients admitted to an emergency department for VKA-related intramuscular hematoma, Am. J. Emerg. Med. (2018), https://doi.org/10.1016/j.ajem.2018.03.067.

[6] J. Bouget, E. Oger, N. Nicolas, Emergency admissions for major haemorrhage associated with antithrombotics: a cohort study, Thromb. Res. (2015), https://doi.org/10.1016/j.thromres.2014.10.029.

[7] Y. Xu, S. Schulman, D. Dowlatshahi, A.M. Holbrook, C.S. Simpson, L.E. Shepherd, et al, Direct oral anticoagulants- or xarfarin-related major bleeding: characteristics, reversal strategies and outcomes from a multicenter observational study, Chest. (2017), https://doi.org/10.1016/j.chest;2017.02.009.

[8] L. Green, J. Tan, J.K. Morris, R. Alikhan, N. Curry, T. Everington, et al, A three-year prospective study of the presentation and clinical outcomes of major bleeding episodes associated with oral anticoagulant use in the UK (ORANGE study), Haematologica. (2018), https://doi.org/10.332/haematol.2017.18220.

[9] C. Beccatini, L. Franco, J. Beyer-Westendorf, L. Masotti, C. Nitti, S. Vanni, et al, Major bleeding with vitamin $\mathrm{K}$ antagonists or direct oral anticoagulants in real-life, Int. J. Cardiol. (2016), https://doi.org/10.1016/j.ijcar.2016.11.117

[10] K. Tazarourte, B. Riou, B. Tremey, C.-M. Samama, E. Vicaut, B. Vigué, EPAHK study group, Guideline-concordant administration of prothrombin complex concentrate and vitamin $\mathrm{K}$ is associated with decreased mortality in patients with severe bleeding under vitamin K antagonist treatment (EPAHK study), Critical Care (2014), https://doi.org/10.1186/cc13843.

[11] V.G. Menditto, F. Fulgenzi, S. Lombardi, A. Dimitriadou, C. Mincarelli, M. Rosati, et al, Management of spontaneous soft-tissue hemorrhage secondary to anticoagulant therapy: a cohort study, Am. J. Emerg. Med. (2018), https://doi.org/10.1016/j.ajem.2018.03.061. 
[12] J. Bouget, F. Balusson, L.M. Scailteux, M. Maignan, P.M. Roy, E. L'her, et al, Major bleeding with antithrombotic agents: a 2012-2015 study using the French nationwide Health Insurance database linked to emergency department records within five areas rationale and design of SACHA study, Fundam. Clin. Pharmacol. (2019), https://doi.org/10.1111/fcp.12444.

[13] J. Bouget, F. Balusson, M. Maignan, L. Pavageau, P.M. Roy, K. Lacut, et al, Major bleeding risk associated with oral anticoagulant in real clinical practice. A multicentre 3year period population-based prospective cohort study, Br. J. Clin. Pharmacol. (2020), https://doi.org/ 10.1111/bcp.14362.

[14] G. Pernod, A. Godiér, C. Gozalo, B. Tremey, P. Sié, French National Authority for Health, French clinical practice guidelines on the management of patients on vitamin $\mathrm{K}$ antagonists in at-risk situations (overdose, risk of bleeding, and active bleeding), Thromb. Res. (2010), https://doi.org/10.1016/j.thromres.2010.06.017.

[15] Schulman S, Kearon C. Subcommittee on Control of Anticoagulation of the Scientific and Standardization Committee of the International Society on Thrombosis and Haemostasis. Definition of major bleeding in clinical investigations of antihemostatic medicinal products in non-surgical patients. J. Thromb. Haemost. (2005), https://doi.org/10.1111/j.1538-7836.2005.01204.x.

[16] A. Guven, G. Sokmen, E. Bulbuloglu, C. Tuncer, Spontaneous abdominal hematoma in a patient treated with clopidogrel therapy: a case report, Ital. Heart. J. (2004)

[17] Z.K. Otrock, J.I. Sawaya, R.C. Zebian, A.T. Taher. Spontaneous abdominal hematoma in a patient treated with clopidgrel and aspirin. Ann. Hematol. (2006), https://doi.org/10.1007/s00277-006-0140-2.

[18] D. Jurisic, M. Doko, E. Glavan, D. Vidovic, K. Matkovic, V. Pitlovic, Spontaneous retroperitoneal haematoma associated with clopidogrel therapy mimicking acute appendicitis, Br. J. Clin. Pharmacol. (2006), https://doi.org/10.1111/j.13652125.2006.02608.x.

[19] A. Watanabe, D.B. Pedroso, F.M. Jorge, T.M. Cunha, A.F. Soares, Spontaneous rectus sheath hematoma associated with low dose of acetylsalicylic acid, Arq. Bras. Cir. Dig. (2014), https://doi.org/ 10.1590/s0102-67202014000100020.

[20] A. Hiraga, Y. Nakagawa, I. Kamitsukasa, T. Suzuki, S. Kuwabara, Muscle hematoma due to antithrombotic treatment for ischaemic stroke, J. Clin. Neurosci. (2015), https://doi.org/10.1016/j.jocn.2015.01.023.

[21] A. Hatjipetrou, D. Anyfantakis, M. Kastanakis, Rectus sheath hematoma: a review of the literature, Int. J. Surg. (2015), https://doi.org/10.1016/j.ijsu.2014.12.015.

[22] G. Marquardt, S. Barduzal Angles, F. Leheta, V. Seifert, Spontaneous haematoma of the iliac psoas muscle: a case report and review of the literature, Arch. Orthop. Trauma. Surg. (2002), https://doi.org/10.1007/s004020100310.

[23] J.F. Llitjos, F. Daviaud, D. Grimaldi, S. Legriel, J.L. Georges, E. Guerot, et al, Ilio-psoas hematoma in the intensive care unit: a multicentric study, Ann. Intensive. Care. (2006), https://doi.org/10.1186/s13613-016-0106-z.

[24] N. Cinar, A. Karaoglan, S. Karsidag, Intramuscular hematomas caused by anticoagulant therapy: Is advanced age a risk factor, Arch. Neuropsychiatry. (2010), 
[25] J. Chew, S. Natesan, W.S. Lim, Spontaneous quadriceps hematoma in an elderly adult taking therapeutic doses of warfarin, J. Am. Geriatr. Soc. (2013), https://doi.org/ 10.1111/jgs.12581.

[26] L. Maeckelbergh, S. Colen, L. Anné, Upper arm compartment syndrome: a case report and review of the literature, Orthop. Surg. (2013), https://doi.org/10.1111/os.12054.

[27] D.C. Zimmerman, T. Kapoor, M. Elfond, P. Scott, Spontaneous compartment syndrome of the upper arm in a patient receiving anticoagulant therapy, J. Emerg. Med. (2013), https://doi.org/10.1016/j.jemermed.2011.09.031.

[28] E. Nourbakhsh, R. Anvari, K. Nugent, Abdominal wall hematomas associated with lowmolecular-weight heparins: an important complication in older adults, J. Am. Geriatr. Soc. (2011), https://doi.org/10.1111/j.1532-5415.2011.03529.x.

[29] W.B. Cherry, PS. Mueller; Rectus sheath hematoma: review of 126 cases at a single institution, Medicine. (Baltimore) (2006), https://doi.org/10.1097/01.md.0000216818.13067.5a.

[30] A. Dohan, M. Sapoval, B.G. Chousterman, M. di Primio, E. Guerot, O. Pellerin, Spontaneous soft-tissue hemorrhage in anticoagulated patients: safety and efficacy of embolization Am. J. Roentgenol. (2015), https://doi.org/10.2214/AJR.14.12578.

[31] C. Gonzalez, S. Penado, L. Llata, C. Valero, J.A. Riancho, The clinical spectrum of retroperitoneal hematoma in anticoagulated patients, Medicine. (Baltimore) (2003), https://doi.org/ 10.1097/01.md.0000085059.63483.36.

[32] O.F. Ozkan, A. Guner, A.B. Cekic, T. Turan, U. Kaya, E. Reis, Iliopsoas hematoma: a rare complication of warfarin therapy, J. Coll. Physicians. Surg. Pak. (2012), https://doi.org/10.2012/JCPSP.673674.

[33] J.L. Tsai, P.J. Yang, H.Y. Lin, C.C. Chang, Spontaneous iliopsoas hematoma, J. Emerg. Med. (2016), https://doi.org/10.1016/j.jemermed.2016.05.030.

[34] R.D. Shah, S. Nagar, C.J. Shanley, R.J. Janczyk, Factors affecting the severity of spontaneous retroperitoneal hemorrhage in anticoagulated patients, Am. J. Surg. (2008), https://doi.org/10.1016/j.amjsurg.2007.12.003. 
Declaration of interests

$\bigotimes$ The authors declare that they have no known competing financial interests or personal relationships that could have appeared to influence the work reported in this paper.

$\square$ The authors declare the following financial interests/personal relationships which may be considered as potential competing interests: 
Data on major muscular hematomas while exposed to any antithrombotic agents are lacking Major muscular hematomas were mostly located in the lower limbs

Iliopsoas location was an independent predictor of in-hospital mortality 